\title{
Exploring Self-reliance and Support Tasks for Parent-dependent Singles
}

\author{
Eun-Mi An1), Jeong-Moo Hurh²)
}

\section{부모에게 의존하는 미혼 독신들을 위한 자립과 부양 과제 탐색$$
\text { 안은미 }{ }^{1)} \text {, 허정무2) }
$$

\begin{abstract}
The purpose of this study is to survey on the exploring self-reliance and support tasks for parent-dependent singles. Based on the results of the study, we tried to suggest ways to support unmarried singles outside their parents' dependence and to establish new family relationships. The following conclusions were drawn based on the results of a survey of adult men and women in their 20s and 30s working in large companies in small and medium cities. First, as the marriage value view that marriage is not a necessity is recently formed, the proportion of unmarried men and women is increasing due to the increase of marriage age. As women's ability to change their lives, being highly educated, low wages and high marriage costs have led to the avoidance of marriage. Second, economically and materially rich unmarried singles are showing their lifestyles instead of receiving sufficient support from their parents. Third, males tend to be economically dependent on their parents as their age increases, whereas females tend to be economically independent. More than half support parental support, nursing and living with parents. While support for nursing is high, support for economic stimulus is rather low. Based on the results of the research, marriage preparation education programs to support adult children designed to help them to become independent from their parents', along with an imploved attitude toward preparing for aging of both parents and adults are suggested. We proposed the development and dissemination of old age preparation program.
\end{abstract}

Keyword: Lifestyle, Parent-dependent Single, Marriage Preparation Education Program, Old Age Preparation Program

\section{요 약}

이 연구의 목적은 미혼 독신들이 부모 의존에서 벗어나 독립할 수 있는 지원 방안 및 새로운 가족

Received(June 13, 2020), Review Result(1st: August 4, 2020, 2nd: September 17, 2020), Accepted(October 28, 2020)

1) (Ph.D. course/doctorate course) 16449 Dept. of Education, Ajou University, 206 World cup-ro, Yeongtong-gu, Suwon, Korea

email: vuddi99@hanmail.net

2) (Professor, Corresponding Author) 27909 Dept. of Early Childhood Education, Korea National Univ. of Transportation, 61 Darhak-ro, Jeungpyeong-gun, Chungcheongbuk-do, Korea

email: jmhuh@ut.ac.kr 


\section{Exploring Self-reliance and Support Tasks for Parent-dependent Singles}

관계 설정 방안을 제시함에 있다. 중소도시의 대기업에 근무하고 있는 20 대와 30 대를 대상으로 설 문조사를 실시한 다음 세 가지 연구 결론을 도출하였다. 첫째, 결혼에 대한 가치관의 변화와 결혼 연령이 높아짐에 따라 미혼 독신으로 지내는 성인 남녀의 비율이 증가하고 있다. 둘째, 부모에게 계 속 의존하면서 지내고 있음에 따라 경제적으로 비교적 풍족한 미혼 독신들의 증가하고 있다. 셋째, 남성의 경우에서는 연령이 증가할수록 부모에게 경제적으로 의존하는 경향이 있지만 여성의 경우에 는 반대로 경제적으로 독립하는 경향이 있다. 부모의 부양, 간호에 대해서는 과반수가 찬성하고 있 다. 간호에 대해서는 높은 찬성률을 보이지만 경제적 부양에 대해서는 지지율이 다소 낮은 편이다. 연구결과에 기초하여 미혼 독신들의 자립을 지원하는 결혼준비교육 프로그램, 고령사회로 진행하면 서 부모 세대와 성인자녀 세대 모두 노후를 준비할 수 있는 태도 전환 및 노년준비 프로그램의 개 발 및 보급을 제안하였다.

핵심어: 생활양식, 부모의존 미혼 독신, 결혼준비교육 프로그램, 노년준비 프로그램

\section{1. 문제의 제기}

대부분이 대학을 진학하게 되고 대학졸업 이후에도 취업난이 가중되면서 청소년기를 지나 성인기 에 도달하였음에도 불구하고 성인의 역할을 제대로 하지 못하는 청년 세대가 증가하고 있다. 높은 실업률이 결혼을 위한 준비기간을 길어지게 하고 결혼지연과 만혼현상을 발생시키는 원인[1]으로 지적되고 있다. 결혼지연과 만혼현상은 필연적으로 미혼독신기간을 연장시키게 된다. 부모의존 미 혼 독신은 성인이 되어 충분히 독립해야 하지만 적극적으로 구직활동을 하지 않고 있으며, 부모로 부터 이가하지 않고 부모집에 함께 거주하면서 부모에게 의존하고 있는 20대 후반에서 40 세 미만 의 미혼 독신자들을 의미하는 것[2]으로 정의된다.

성인됨의 기준은 일정한 연령에 도달하거나 결혼, 출산 등과 같은 생애 전이를 경험하여 그에 합당한 역할을 수행하면서 인정된다. 생애 전이를 경험하여 역할 지위를 획득하는 것은 그 역할을 수행할 수 있는 능력을 지닌 것을 의미하므로 연령과 생애 전이 경험 여부가 성인됨의 기준[3]이 되어 왔다. 그러나 최근에는 성인기 이행에 소요되는 시간이 길어짐에 따라, 사회적으로 성인으로 인정되는 연령이지만 결혼을 하기 전까지 지속적으로 부모집에 계속 머물면서 살아가는 성인들이 많아지고 있는 추세[4][5]이다. 이들은 대부분 대학졸업 후 바로 취업으로 연결되지 못할 경우 부모 에게 의존하면서 취업준비를 하고 있다. 부모로부터의 독립이 어려워지고 생애과정의 지연과 경제 위기는 성인 미혼 남녀가 부모에게 의존하는 기간을 연장시키고 있는 것이다. 부모의 입장에서 보 면 독립하지 않고 경제적으로 의존하는 성인 자녀는 경제적인 부담뿐만 아니라 심리적 스트레스 요인이 될 수 있다. 심한 경우에는 부모를 비롯한 가족구성원 모두에게 정서적인 긴장을 야기시켜 가족갈등을 심화시키고 가족기능의 약화를 초래[6][7]하기도 한다.

평균수명의 연장으로 부모 세대가 장수함에 따라 자녀가 부모를 부양하거나 간병하는 시기는 자녀 세대의 중년기 이후로 연기되었다. 그러나 부모 세대로부터 자녀 세대로의 물심양면의 원조 는 부모 세대가 고령기에 들어선 다음에는 부모에 대한 사적 간병이나 부양을 충분히 가능하게 할 것인가의 문제가 대두된다. 부모가 고령기에 도달한 단계에서의 부모-자녀 관계에서는 부모가 경제 적 부양과 신체적 간호가 필요한 의존자로 입장이 바뀌게 되는 것이다. 초고령사회로의 진행과 함 께 간병을 필요로 하는 고령자의 수는 계속 증가할 것으로 예상된다. 부모의존 미혼독신자녀 세대 
에 대한 중년기 부모 세대의 일방적인 서비스 및 경제적 지원은 부모 세대의 막연한 노후불안에 대한 보장이라는 측면에서 이루어지는 측면도 있다. 평균수명의 연장과 함께 노년기가 길어짐에 따라 부모 세대는 자신들의 노후를 더 이상 자녀 세대나 국가에 의지할 수 없이 스스로 준비해야 만 하는 과제가 대두되었다. 이제부터는 성인 자녀 세대와 중년기 부모세대 모두 급속한 고령화의 진행에 따라 의존이 아니라 각자 독립해서 준비해야만 하는 시대에 직면하였기 때문에 부모-자녀 관계에 있어서도 새로운 모델[8]이 설정되어야 한다.

이 연구의 목적은 부모로부터 독립하지 못하고 있는 미혼 독신자들의 생활양식을 조사한 결과 를 토대로 부모의존에서 벗어나 독립할 수 있는 지원 방안 및 새로운 가족관계 설정 방안을 제시 하고자 함에 있다.

\section{2. 연구 방법}

이 연구는 지방 중소도시에 거주하고 대기업에 근무하는 20 대와 30 대의 남녀 직장인 120 명을 임의 표집하여 연구대상으로 선정하였다. 연구대상의 인구사회학적 배경은 연령별로는 20대가 남녀 각 각 30명으로 60 명으로 나타났다. 마찬가지로 30 대의 경우에도 남녀 각각 30명으로 60 명으로 나타 났다. 학력 수준별로는 모두 대졸 이상으로 나타났으며, 120 명 가운데 42 명은 대학원 졸업 이상으 로 나타났다.

생활양식 조사를 위한 설문지는 모두 9문항으로 구성하였다. 인구사회학적 배경을 조사하기 위 한 3문항(성, 연령, 학력 수준)과 생활양식에 관한 6문항(경제적 자립의 정도, 부모의 노후에 경제 적으로 지원하는 것에 대한 찬반 여부, 결혼 후 친부모와의 동거에 대한 찬반 여부, 성인자녀가 부 모와 별거해야 하는 것에 대한 찬반 여부, 장남의 특별한 역할에 대한 찬반 여부, 자식의 성별에 의한 책임의 차이에 대한 찬반 여부)으로 구성하였다. 가족학 전공 교수 2 인에게 의뢰하여 안면 타 당도 검사를 실시한 다음 최종 문항으로 확정하였다. 2020년 4월 응답자들이 근무하는 회사를 연 구진이 직접 방문한 다음, 회사 관계자의 협조를 구해서 설문조사를 실시하고 현장에서 모두 회수 하였다(회수율 $100 \%$ ).

\section{3. 연구 결과}

부모의존 미혼 독신들에게 있어서 경제적 자립은 성인기로 가는 중요한 이정표이다. 부모-자녀 관 계에 있어서 경제적 자립의 정도에 대한 인식을 조사한 결과는 [표 1]에 제시한 바와 같다.

[표 1]에 의하면, 경제적 자립에 대해서 20대 남성의 $65.9 \%$ 는 자립하고 있지 않거나 거의 자립하 고 있지 않는 편으로 응답하고 있다. 그러나 20대 여성의 $77.5 \%$ 는 자립하고 있거나 거의 자립하는 편으로 응답하고 있다. 30 대 남성의 경우에는 $68.4 \%$ 가 자립하고 있지 않거나 거의 자립하고 있지 않는 편으로 응답하고 있다. 30 대 여성의 경우에는 $55.5 \%$ 가 자립하고 있거나 거의 자립하는 편으 
로 응답하고 있다.

[표 1] 경제적 자립의 정도

[Table 1] Degree of Economic Independence

\begin{tabular}{ccccc}
\hline 구 분 & 자립하고 있음 & $\begin{array}{c}\text { 거의 } \\
\text { 자립하고 있음 }\end{array}$ & $\begin{array}{c}\text { 거의 자립하고 } \\
\text { 있지 않음 }\end{array}$ & $\begin{array}{c}\text { 자립하고 있지 } \\
\text { 않음 }\end{array}$ \\
\hline \multirow{2}{*}{20 대 남성 } & 11 & 9 & 12 & 28 \\
& $(18.2)$ & $(15.9)$ & $(19.3)$ & $(46.6)$ \\
20 대 여성 & 24 & 21 & 10 & 5 \\
& $(40.0)$ & $(37.5)$ & $(15.0)$ & $(7.5)$ \\
30대 남성 & 8 & 11 & 15 & 26 \\
& $(12.6)$ & $(18.9)$ & $(25.2)$ & $(43.2)$ \\
30 대 여성 & 14 & 19 & 16 & 11 \\
& $(23.8)$ & $(31.7)$ & $(27.0)$ & $(17.5)$ \\
\hline
\end{tabular}

자립의 과제는 연령의 증가와 함께 서서히 진행되는 것이 일반적이지만, 남성의 경우에 있어서 는 오히려 연령이 상승할수록 부모에게 경제적으로 의존하는 경향이 더 높은 것을 알 수 있다. 반 대로 여성들의 경우에는 연령이 증가할수록 부모로부터 경제적으로 독립하는 비율이 더 높게 나타 났다는 것을 알 수 있다.

부모-자녀 관계에 있어서 부모의 부양규범을 알아보기 위해 부모의 노후는 자식이 경제적으로 돌봐드려야 한다는 노부모의 경제적 부양에 대한 찬반 여부를 조사한 결과는 [표 2]와 같다.

[표 2] 부모의 노후는 자식이 경제적으로 지원해야 한다는 것에 대한 찬반 여부

[Table 2] Pros and Cons of Economic Support for Older Parents

\begin{tabular}{ccccc}
\hline 구 분 & 찬성함 & 다소 찬성함 & 다소 반대함 & 반대함 \\
\hline \multirow{2}{*}{20 대 남성 } & 31 & 23 & 3 & 3 \\
& $(51.7)$ & $(38.3)$ & $(5.5)$ & $(3.4)$ \\
20 대 여성 & 30 & $(38.3)$ & 7 & - \\
& $(50.0)$ & 25 & $(11.7)$ & $(0.0)$ \\
30대 남성 & 14 & $(41.6)$ & 10 & 11 \\
& $(23.3)$ & 25 & $116.7)$ & $(18.4)$ \\
30 대 여성 & 11 & $(41.6)$ & $(21.6)$ & $(18.4)$ \\
\hline
\end{tabular}

[표 2]에 의하면, 부모의 노후는 자식이 경제적으로 지원해야 한다는 것에 대해서 20대 남성의 $90.0 \%$ 와 20 대 여성의 $88.3 \%$ 가 찬성하고 있어서 찬성률이 높게 나타났다. 그러나 30 대 남성의 경우 에는 $64.9 \%$, 여성의 경우에는 $60.0 \%$ 가 찬성하고 있어서 20 대에 비해 찬성률이 낮게 나타났다.

노부모에게 간호가 필요해졌을 경우 자식이 돌보아야 한다는 노부모의 간호에 대한 찬반 여부 
를 조사한 결과는 [표 3] 같다.

[표 3] 연로한 부모는 자식이 간병해야 한다는 것에 대한 찬반 여부

[Table 3] Pros and Cons of Nursing Care for Older Parents

\begin{tabular}{ccccc}
\hline 구 분 & 찬성함 & 다소 찬성함 & 다소 반대함 & 반대함 \\
\hline \multirow{2}{*}{20 대 남성 } & 38 & 18 & 2 & 2 \\
& $(62.3)$ & $(30.8)$ & $(3.4)$ & $(3.5)$ \\
20 대 여성 & 40 & 18 & 2 & - \\
& $(67.0)$ & $(30.1)$ & $(2.9)$ & $(0.0)$ \\
30대 남성 & 25 & 26 & 5 & 4 \\
& $(41.6)$ & $(43.3)$ & $(8.4)$ & $(6.7)$ \\
30대 여성 & 23 & 28 & 6 & 3 \\
& $(38.2)$ & $(47.0)$ & $(9.5)$ & $(5.3)$ \\
\hline
\end{tabular}

[표 3]에 의하면, 연로한 부모는 자식이 간병해야 한다는 것에 대해서 20 대 남성의 $93.1 \%$ 와 20 대 여성의 $97.1 \%$ 가 찬성하고 있어서 찬성률이 높게 나타났다. 그러나 30 대 남성의 경우에는 $84.9 \%$, 여성의 경우에는 $85.0 \%$ 가 찬성하고 있어서 20대에 비해 찬성률이 낮게 나타났다.

부모의 거주 규범을 알아보기 위해 노후는 결혼한 자식 중 누군가와 동거하는 것이 바람직스럽 다는 결혼 후의 친부모와의 동거에 대한 찬반 여부를 조사한 결과는 [표 4]와 같다.

[표 4] 결혼 후 친부모와의 동거에 대한 찬반 여부

[Table 4] Pros and Cons of Living with Parents After Marriage

\begin{tabular}{ccc|c|c}
\hline 구 분 & 찬성함 & 다소 찬성함 & 다소 반대함 & 반대함 \\
\hline \multirow{2}{*}{ 20대 남성 } & 17 & 26 & 13 & 4 \\
& $(28.8)$ & $(43.2)$ & $(21.2)$ & $(6.8)$ \\
20대 여성 & 16 & 28 & 12 & 4 \\
& $(26.8)$ & $(47.4)$ & $(19.6)$ & $(6.2)$ \\
30대 남성 & 11 & 15 & 18 & 16 \\
& $(17.0)$ & $(25.0)$ & $(30.3)$ & $(27.4)$ \\
30대 여성 & 7 & 16 & 17 & 20 \\
& $(10.2)$ & $(26.9)$ & $(28.6)$ & $(34.3)$ \\
\hline
\end{tabular}

[표 4]에 의하면, 결혼 후 친부모와의 동거에 대한 찬반 여부에 대해서 20대 남성의 $72.0 \%$ 와 20 대 여성의 $74.2 \%$ 가 찬성하고 있어서 찬성률이 높게 나타났다. 그러나 30 대 남성의 경우에는 $42.0 \%$, 여성의 경우에는 $37.1 \%$ 가 찬성하고 있어서 20대에 비해 찬성률이 낮게 나타났다.

부모의 부양, 간호 및 결혼 후의 친부모와의 동거에 관해서는 찬성이 과반수 이상을 차지하고 있다. 이 중에서 가장 높은 찬성률을 나타내는 것은 간호에 대해서이며, 20 대와 30 대 모두 남녀를 
불문하고 높은 지지율을 나타내고 있다([표 3] 참조). 경제적 부양에 대해서는 간호보다는 지지율이 약간 낮은 편이다([표 2] 참조). 연령대에 의한 차이가 가장 확실히 나타난 것은 결혼 후 친부모와 의 동거에 대해서이며, 30대에서 동거 지지율이 낮은 편이다([표 4] 참조).

자식이 성인이 된 후 결혼했건 안 했건 부모와 별거해야 한다는 성인이 된 자식과의 별거에 대 한 찬반 여부를 조사한 결과는 [표 5]와 같다.

[표 5] 성인자녀는 부모와 별거해야 한다는 것에 대한 찬반 여부 [Table 5] Pros and Cons of Separation from an Adult Child

\begin{tabular}{ccccc}
\hline 구 분 & 찬성함 & 다소 찬성함 & 다소 반대함 & 반대함 \\
\hline \multirow{2}{*}{20 대 남성 } & 8 & 20 & 23 & 9 \\
& $(13.0)$ & $(33.6)$ & $(37.7)$ & $(15.8)$ \\
20 대 여성 & 6 & 16 & 25 & 13 \\
& $(8.6)$ & $(26.3)$ & $(42.6)$ & $(22.5)$ \\
30 대 남성 & 10 & 10 & 19 & 21 \\
& $(16.0)$ & $(17.6)$ & $(31.9)$ & $(34.6)$ \\
30 대 여성 & 9 & 14 & 18 & 19 \\
& $(13.0)$ & $(23.0)$ & $(30.7)$ & $(33.3)$ \\
\hline
\end{tabular}

[표 5]에 의하면, 성인자녀는 부모와 별거해야 한다는 것에 대한 찬반 여부에서 20대 남성의 $46.6 \%$ 와 20 대 여성의 $34.9 \%$ 가 찬성하고 있어서 찬성률이 낮게 나타났다. 그러나 30 대 남성의 경우 에는 $33.6 \%$, 여성의 경우에는 $36.0 \%$ 가 찬성하고 있어서 20 대에 비해 찬성률이 더 낮게 나타났다.

결혼 후 친부모와의 동거에 대한 지지율이 상대적으로 낮다고 해도 결혼 후 부모와의 별거가 지지받고 있는 것은 아니다는 것을 알 수 있다. 자식이 성인이 된 후 결혼했건 하지 않았건 부모 와는 별거해야 한다는 사고에 대해 연령대를 불문하고 어느 연령대에서도 과반수 이상이 동조하고 있지 않다는 것을 알 수 있다. 명확한 동거 규범이 약해지는 양상을 보이고 있지만 그렇다고 해서 서구형의 별거 규범도 존재하고 있지 않은 것을 볼 때, 결혼 후 부모와의 동거 및 별거는 상황과 부모-자녀간의 구체적인 관계(친부모, 처가 부모 등)에 의해 선택되는 상황규정적인 것이라는 것을 알 수 있다. 이 연구에서는 결혼 후 부모와의 동거를 남성과 여성 모두 친부모로 한정하여 조사하 였지만, 남성의 경우에는 친부모와 처가 부모, 여성의 경우에는 친부모와 시부모로 구분하여 조사 하면 다른 결과가 나올 것으로 예측된다. 그만큼 결혼 후 부모 부양에 대한 태도는 남성과 여성이 각자 처한 상황에 따라 다르게 규정될 수 있을 것으로 볼 수 있기 때문이다.

부모-자녀 관계에 있어서 부모의 자식역할 규범을 알아보기 위해 장남에게는 특별한 역할이 있 다는 장남의 특별한 역할에 대한 찬반 여부를 조사한 결과는 [표 6]과 같다. 
[표 6] 장남의 특별한 역할에 대한 찬반 여부

[Table 6] Pros and Cons of the Eldest Son's Special Role

\begin{tabular}{ccccc}
\hline 구 분 & 찬성함 & 다소 찬성함 & 다소 반대함 & 반대함 \\
\hline \multirow{2}{*}{20 대 남성 } & 9 & 20 & 14 & 17 \\
& $(14.4)$ & $(33.6)$ & $(24.0)$ & $(28.0)$ \\
20 대 여성 & 9 & 19 & 21 & 11 \\
& $(13.9)$ & $(32.1)$ & $(34.9)$ & $(19.1)$ \\
30 대 남성 & 12 & 18 & 11 & 19 \\
& $(20.0)$ & $(28.8)$ & $(19.1)$ & $(32.1)$ \\
30 대 여성 & 7 & 17 & 13 & 23 \\
& $(12.1)$ & $(28.0)$ & $(21.6)$ & $(38.3)$ \\
\hline
\end{tabular}

[표 6]에 의하면, 장남의 특별한 역할에 대한 찬반 여부에서 20대 남성의 $48.0 \%$ 와 20대 여성의 $46.0 \%$ 가 찬성하고 있어서 찬성률이 낮게 나타났다. 그러나 30 대 남성의 경우에는 $48.8 \%$, 여성의 경우에는 $40.1 \%$ 가 찬성하고 있어서 20 대에 비해 여성들의 찬성률이 더 낮게 나타났다. 30 대보다 젊은 20대 특히, 여성들의 경우 장남에게는 특별한 역할이 있다는 전통적인 장남 규범이 약해지고 있음을 알 수 있다.

아들과 딸은 부모에 대한 책임이 다르다는 자식의 성별에 의한 책임의 차이에 대한 찬반 여부 를 조사한 결과는 [표 7]과 같다.

[표 7] 자식의 성별에 의한 책임의 차이에 대한 찬반 여부

[Table 7] Pros and Cons of Differences in Responsibility by Gender of Child

\begin{tabular}{ccccc}
\hline 구 분 & 찬성함 & 다소 찬성함 & 다소 반대함 & 반대함 \\
\hline \multirow{2}{*}{20 대 남성 } & 12 & 16 & 16 & 17 \\
& $(19.9)$ & $(26.0)$ & $(26.0)$ & $(28.1)$ \\
20 대 여성 & 6 & 11 & 20 & 23 \\
& $(10.4)$ & $(18.3)$ & $(33.0)$ & $(38.3)$ \\
30대 남성 & 6 & 14 & 11 & 29 \\
& $(10.4)$ & $(23.0)$ & $(18.3)$ & $(48.3)$ \\
30대 여성 & 5 & 9 & 16 & 30 \\
& $(8.3)$ & $(15.7)$ & $(26.0)$ & $(50.0)$ \\
\hline
\end{tabular}

[표 7]에 의하면, 자식의 성별에 의한 책임의 차이에 대한 찬반 여부에서 20 대 남성의 $45.6 \%$ 와 20 대 여성의 $28.7 \%$ 가 찬성하고 있어서 찬성률이 낮게 나타났다. 그러나 30 대 남성의 경우에는 $33.4 \%$, 여성의 경우에는 $24.0 \%$ 가 찬성하고 있어서 20 대에 비해 찬성률이 더 낮게 나타났다.

장남에 국한하지 않고 자식의 성별에 의해 부모에 대한 책임이 다르다는 사고방식에는 어느 연 


\section{Exploring Self-reliance and Support Tasks for Parent-dependent Singles}

령층에서도 찬성하는 비율이 적다는 것을 알 수 있다. 특히 30 대 여성들의 찬성 의견이 낮게 나타 났으므로 연령대를 불문하고 여성들의 경우에서 차이를 인정하지 않는 비율이 남성들보다 상대적 으로 더 높다는 것을 알 수 있다.

[표 6]과 [표 7]의 결과를 종합해 볼 때, 해방 이후의 민주주의 교육이 정착되면서 남녀평등사상 이 반영된 결과로 볼 수 있겠지만, 무엇보다도 출생률 감소에 따라 부모에 대한 책임을 아들이건 딸이건 구별할 수 있는 시대는 아님을 보여준다고 볼 수 있다.

\section{4. 논의 및 결론}

이 연구의 대상인 부모의존 미혼 독신들은 소산소사형의 가족관계를 통해 성장한 세대로서, 부모 세대에 비해 풍족한 유년과 청소년 시기를 보냈다. 평생을 통한 부모-자녀 관계의 모습은 부모-자 녀 각자의 동시집단의 조합에 의해 형성된 가족관계이다. 20 대 후반에서 30 대에 걸친 성인자녀 세 대와 40대 후반에서 60 대에 걸친 부모 세대이다. 이들 부모 세대는 고도성장기에 노동시장에서 일 하며 우리나라 경제발전을 지탱해 온 베이비붐 세대이다.

그러나 현재 경제위기가 도래하면서 중산층 의식은 그 기반이 무너지고 있다. 성인자녀 세대의 자립을 촉진하는 부모-자녀 관계로 의식과 행동이 변화될 필요성이 있으며 부모 세대가 이를 적극 주도해야만 한다. 부모집에 항상 머물면서 무조건 의존하면서 살 수 있는 상황이 아니기 때문이다.

현재 결혼연령이 높아지면서 결혼을 미루고 있는 미혼 독신자들이 증가하고 있는 것도 문제이 지만 급속한 고령화도 진행되고 있다. 이에 따라 성인 자녀들에게는 결혼을 통해 자립할 수 있도 록 지원하는 결혼준비교육 프로그램이 요구된다. 급속하게 진행하고 있는 고령사회에 대비하기 위 해서는 중년기 부모 세대 및 성인자녀 세대 모두 노후에 자립적으로 생활하기 위한 노년준비 프로 그램의 개발 및 보급도 요구된다.

이 연구에서는 제한된 연령집단과 대상에 국한하여 설문조사하였기 때문에 연구결과를 일반화 하는 데 있어서 한계가 있을 수 있다. 지역별 그리고 연령별 대상을 확대하는 등 표본을 확대하여 조사를 실시하고 그 차이를 비교할 때 일반화가 가능할 수 있다.

\section{References}

[1] H. J. Yoo, S. M. Hyun, The Effects of Economic Resources on Marriage-Delaying, Korea Journal of Population Studies, (2010), Vol.33, No.1, pp.75-101, UCI: G704-000152.2010.33.1.006

[2] Y. B. Lee, Y. W. Lee, H. J. Choi, H. Y. Lee, An Explorative Study on Coresident Adult Children in Korea, Korean Journal of Family Social Work, (2011), No.31, pp.5-30, DOI: 10.16975/kjfsw.2011..31.001

[3] E. Y. Hong, Attitude towards marriage among unmarrieds and the effect of their dependence on parents, 
[4] S. A. Park, Analysis of Main Causes and Processes of the Postponement of Marriage by Unmarried People at a Late Age using Grounded Theory, University of Ulsan, Master's thesis, (2016)

[5] J. E. Lee, An Intergrated Study on Determinants of Marriage Intentions among Unmarried Women, Pyeongtaek University, Doctor's thesis, (2017)

[6] W. S. Aquilino, Two Views of One Relationship: Comparing Parents' and Young Adult Children's Reports of the Quality of Intergenerational Relations, Journal of Marriage and the Family, (1999), Vol.61, No.4, pp.858-870, DOI: $10.2307 / 354008$

[7] B. A. Mitchell, E. M. Gee, "Boomerang Kids" and Midlife Parental Marital Satisfaction, Family Relations, (1996), Vol.45, No.4, pp.442-448, DOI: $10.2307 / 585174$

[8] J. P. Lee, Increasing Parasitic Singles Economic Decline: Lessons from Japan's Parasitic Singles Growth, Weekely Economy, (2015), Vol.614, pp.21-29. 